\title{
Desvelando os discursos da modernidade no regimento interno de uma escola pública do Rio de Janeiro
}

\author{
Alexandre Florencio dos Santos \\ PUC-Rio
}

\begin{abstract}
Resumo
Este artigo tem por objetivo revelar o discurso da modernidade subjacente ao regimento interno de uma escola pública do município do Rio de Janeiro. Com base nos pressupostos teóricos da LA contemporânea (FABRÍCIO, 2006; MOITA LOPES, 2006 e 2013; BOHN, 2013) faço uma breve análise dos discursos emanados do Regimento Escolar da SME e do Regimento Interno de uma escola pública. Procuro também evidenciar como esses discursos se fazem presentes no imaginário dos alunos e reflito sobre alternativas no sentido de se alcançar uma melhor qualidade de vida.
\end{abstract}

Palavras-chave: discurso, modernidade, disciplina

\begin{abstract}
The aim of this article is to discuss the discourse of modernity underlying the internal regulations of a public school in Rio de Janeiro. Based on contemporary LA theoretical postulates (Fabrício, 2006; Moita Lopes, 2006 e 2013; Bohn, 2013), I briefly analyze the discourses from the educational regulations of SME and from the internal regulation of a public school. I also focus on how these discourses are present in students' conceptions, and I reflect on alternatives that could lead to a better quality of life at schools.

Keywords: discourse, modernity, discipline
\end{abstract}

\section{INTRODUÇÃO}

Entendemos que as práticas discursivas educacionais são parte da vida cotidiana. Além disso, concebemos também que esse discurso, como prática social, não é um elemento neutro nas interações, mas um poderoso instrumento de transmissão de ideologias e valores aos educandos. Assim sendo, a proposta deste trabalho é analisar criticamente o regimento interno de uma unidade escolar integrante da rede pública do município do Rio de Janeiro, onde atuei como professor, encaminhando meu raciocínio 
à luz das reflexões da LA (Moita Lopes, 2006 e Fabricio, 2006, dentre outros)

Ora, se considerarmos que a Linguística Aplicada pode ser definida atualmente como uma ciência de caráter interdisciplinar que aborda problemas sociais envolvendo a linguagem (DAVIES, 1999) e que a escola possui lugar de destaque na sociedade, com um papel de transmissora do legado cultural e científico, de formadora de futuros cidadãos e de transformadora da realidade social na qual está inserida (NOVAIS, 2008), a proposta deste trabalho é, norteados pelas reflexões mais recentes da LA, analisar criticamente os discursos manifestos no regimento interno de uma da rede pública do município do Rio de Janeiro, buscando desvelar seus conteúdos subjacentes. Afinal, conforme Souza (apud NOVAIS, 2008), a escola ainda mostra-se como ponto de referência para os estudos de vida em sociedade.

\section{O REGIMENTO INTERNO E O DISCURSO DA MODERNIDADE}

Entende-se por regimento interno o "conjunto de normas e procedimentos que regulam a vida de uma organização" (VIDAL, CÁRAVE E FLORENCIO, 1992, apud WATANABE, 1999, p.38) ou, no âmbito escolar, o conjunto de normas e procedimentos que a instituição gera para possibilitar a regulação da convivência (ANTÚNEZ, 1988). Por fim, o regimento interno é considerado por alguns, inclusive, como parte do projeto educativo ou como um de seus complementos necessários.

Para entender que vozes são manifestas no objeto de nossa pesquisa, cumpre esclarecer que o regimento em questão (doravante, RI) foi redigido com base no regimento escolar ${ }^{1}$ da Secretaria Municipal de Educação (SME); este último, conforme declaração feita pela então secretária municipal de educação, "instrumentaliza os diretores e professores, valoriza seu trabalho e norteia o comportamento dos alunos."2 Para ela, a publicação da resolução que trata do Regimento Escolar constitui-se num marco porque

[a]lém de nortear o comportamento dos alunos, o regimento escolar resgata a

1 Regimento Escolar Básico do Ensino Fundamental da Rede Pública do Município do Rio de Janeiro, Resolução n ${ }^{\circ} 1074$ da Secretaria Municipal de Educação (SME). Disponível em: http://doweb.rio.rj.gov.br/visualizar_pdf.php?edi_id=1116\&page=1 $\square$. Acesso em: 12/12/14. 2 Disponível em: $\square$ http://www.rio.rj.gov.br/web/sme/exibeconteudo?id=693768 $\square \square \square$ Acesso em:2/12/14. 
autoridade do professor e faz com que os alunos passem a respeitá-lo mais. (...) é um instrumento de trabalho de diretores e professores, para que possam ensinar em um ambiente tranquilo. (...) têm como objetivo estabelecer uma cultura de paz e garantir às nossas crianças o direito de aprender e sonhar com um futuro. ${ }^{3}$

Como professor regente de três turmas (cerca de 90 alunos, de 12 a 16 anos) em uma escola pública municipal, sinto (mais do que percebo) a utilidade do estabelecimento de regras (ou imposição de limites) em prol do bem-estar coletivo. Contudo, inquieta-me o discurso contido no RI e o modo pelo qual os alunos são informados de seus deveres; porventura seria esse o tipo de "educação pautada pelo bem-estar do Estado e, particularmente, pelo exercício do poder sobre as mentes e os corpos dos alunos" sobre o qual Duarte (2006, apud BOHN, 2013, p.82) nos fala? Darse-ia o caso de estruturas rígidas como a do RI problematizado estarem impossibilitando a escola de assimilar as diferenças de cultura, fato que, por sua vez, contribuiria para a escola banir de seu espaço tudo que foge dos padrões estabelecidos? (REBELO, 2002, apud NOVAIS, 2008)

Ciente de que "nossas observações e descrições de eventos não são neutras" (FABRÍCIO, 2006, p.60), "não tentando encaminhar soluções" (MOITA LOPES, 2006a, p.20), mas cônscio de que "pensar alternativas para a vida social é parte intrínseca dos novos modos de teorizar e fazer LA" (idem, p.22), este artigo pretende questionar se "mostrar ao aluno suas deficiências disciplinares (...) e sua inadequação comportamental" (BOHN, 2013, p.81) - papel fulcral do RI, ao que nos parece - seja o caminho mais adequado para o auxílio à "valorização do trabalho do professor", ao "resgate de sua autoridade" e ao "estabelecimento de uma cultura de paz", conforme propagou-se à época de sua publicação em Diário Oficial.

Em outras palavras, tais estatutos realmente favorecem a condução da escola rumo às condições e objetivos mencionados acima (cultura de paz, por exemplo) ou não se assemelhariam mais, em determinados momentos, a um tipo de violência institucional, em que "o Estado faz uso de práticas autoritárias herdadas do período da ditadura militar em nome da manutenção da lei, da ordem e, portanto, do controle social"? (ILANUD, [S.D])

A despeito das respostas a essas questões, algo que fica patente aos olhos de toda a comunidade escolar (pais, alunos, funcionários administrativos, professores, direção

3 idem 
etc.) é o fato de que práticas disciplinares típicas da Modernidade - como o RI, com seu caráter excessivamente restritivo (os três primeiros itens começam com a expressão "É proibido") - não têm dado conta de responder às necessidades da escola na modernidade recente. Não é difícil entender tal fracasso se considerarmos as patentes mudanças de natureza histórica, econômica, cultural, tecnológica e política pelas quais atravessam as sociedades em que vivemos.

\section{O discurso da modernidade}

Outrora, a modernidade desenvolveu a concepção de que a criança precisa da orientação e controle adulto, mais especificamente do Estado (NOVAIS, 2008). Entendia também que ser aluno significava "adquirir atitudes de pontualidade, obediência, silêncio e autodomínio", e moldava os mesmos através de práticas que mantinham uma rígida disciplina sobre o aluno (idem, p.32), com o objetivo de levar a sociedade ao progresso e ao desenvolvimento.

Hoje, urge que se lance um olhar crítico sobre práticas como essas, bastante imbuídas de valores positivistas. Assim, em lugar de princípios antes inquestionáveis tais como o da neutralidade, da descontextualização e da essencialização identitária (MOITA LOPES, 2013b), busca-se hoje uma prática que "inclua os alunos como pessoas que buscam entendimentos" e também [perceba] que professores e alunos desenvolvem simultaneamente seus entendimentos sobre o que estão fazendo como professores e alunos." (ALLWRIGHT, 2006 apud MILLER, 2013, p.103).

O intuito é que procedendo assim estejamos no caminho de instaurar novas práticas sociais a fim de que, paulatinamente, o modelo de referência vigente vá cedendo lugar a mudanças (FREIRE E LEFFA, 2013) que valorizem a qualidade de vida dentro do ambiente escolar, uma vez que, como Fabrício (2006, p.48), entendemos que "nossas práticas discursivas não são neutras, e envolvem escolhas (intencionais ou não) ideológicas e políticas, atravessadas por relações de poder, que provocam diferentes efeitos no mundo social."

\section{O regimento escolar e o RI}

Segundo Fabrício (2006, p.60), é princípio da LA contemporânea "historicizar o objeto, compreendendo como foi produzido, dentro de qual regime de verdade, 
respondendo a quais conjunturas históricas e socioculturais e com qual pressupostos." Certo da impossibilidade de alcançar tal objetivo num trabalho dessa natureza, passo mesmo assim, nas brevíssimas linhas que se seguem, a tentar contextualizar/caracterizar o regimento escolar e o regimento interno da Escola Municipal Cientista Mário Kröeff.

Para Watanabe (1999, p.40) um regimento escolar tem como objetivo "assegurar o alcance, com maior êxito possível, dos objetivos educacionais a que a escola (ou rede de escolas) se propõe"; serve também como "instrumento de organização administrativa, didática e disciplinar de uma comunidade" (idem). Nessa perspectiva, cuida da regulamentação dos direitos e deveres dos membros da comunidade escolar bem como do controle de sua conduta, acabando por se constituir numa espécie de lei interna da escola, que define os direitos e deveres aos quais devem se submeter todos os que se vinculam a ela (ibidem).

O Regimento Escolar Básico do Ensino Fundamental da Rede Pública do Município do Rio de Janeiro foi construído pela SME, gestora de uma rede que atende a 664.384 alunos nas suas 1.009 escolas $^{4}$. A missão dessa secretaria é a de "elaborar a política educacional do município, coordenar sua implantação e avaliar os resultados" buscando "assegurar a excelência na Educação Pública no Ensino Fundamental e na Educação Infantil, além de contribuir para formar indivíduos autônomos e habilitados a se desenvolver profissionalmente e como cidadãos."

Com base nesse regimento é que se construiu o RI que ora analisamos. Também para sua confecção buscou-se respaldo na Lei 4734 de 4 de janeiro de $2009^{7}$, que trata da proibição do uso de celulares (ou aparelhos eletrônicos similares) nas salas de aula. Não nos foi informado quando o RI foi elaborado ou como se deu sua construção. Foinos dito apenas que alguns professores da unidade escolar contribuíram para isso.

Antes de ser redigido pela direção e por alguns professores, conforme relato da direção da escola, "foi feito (elaborado) um sugerido pela própria SME (orientações gerais)". Tal informação é bastante significativa para as reflexões que se seguirão na medida em que, nessas condições, é de se esperar que o discurso da secretaria (sobre seus alvos para a educação pública) e o que se descortina no RI em foco neste trabalho

4 Disponível em http://www.rio.rj.gov.br/web/sme/conheca-a-secretaria. Acesso em: 12/12/14.

5 Idem.

6 Ibidem (grifo meu)

7 Disponível em: <http://cm-rio-de-janeiro.jusbrasil.com.br/legislacao/255337/lei-4734-08>. Acesso em: 12/12/14. 
apontem para uma mesma direção, revelando os mesmos princípios norteadores. Num primeiro momento, tem-se a impressão de que é desse modo que as coisas sucedem, pois o RI em questão reproduz quase que integralmente os artigos 21 (São deveres do aluno) e 22 (Não será permitido) do capítulo V (Do Corpo Discente) do Regimento Escolar da SME.

Por fim, ainda segundo a direção da escola, tem-se recorrido ao RI "muitas vezes, sendo excelente para o andamento e disciplina da escola." Sobre adaptações ou alterações, o documento parece mumificado, pois, a despeito de vivermos em um mundo de céleres e significativas transformações, uma das poucas coisas que têm sido alteradas ao longo desses últimos anos no RI é o horário de entrada e saída dos turnos da manhã e da tarde.

\section{CONSIDERAÇÕES SOBRE OS DISCURSOS DA SME O DO RI}

Diante do exposto acima, recorro outra vez ao pensamento de Fabrício (2006, p.59), segundo a qual um dos procedimentos que vem inspirando a LA contemporânea é o de "interrogar-nos acerca da relevância social da temática e dos objetivos gerais de nossos estudos, tendo em vista os atores sociais que vivenciam as práticas envolvidas no fenômeno a ser focalizado." Tal ideia, com a qual compactuo, é que legitima as reflexões feitas a seguir.

Primeiramente, chama-nos a atenção constar como um dos alvos da SME a busca pela excelência (a nosso ver, uma sobrevalorização da eficiência em detrimento da reflexão no fazer pedagógico) na educação pública; sob certa ótica, esse discurso torna-se admissível ao compreendermos que a escola atual ainda se apresenta majoritariamente como uma instituição moderna, cuja proposta ainda é a mesma de 400 anos atrás, isto é, a de que:

\footnotetext{
cada cidadão deveria receber o tipo de formação mais adequada para poder tornar-se útil e dar os melhores rendimentos possíveis para o sistema econômico e o bem-estar social. Dentro deste contexto, a escola atuaria como uma antecipação da fábrica, ou como um contexto adaptativo que se colocaria entre as relações familiares e as do trabalho assalariado. (NOVAIS, 2008, p.34)
}

Além da procura constante pela melhora de resultados, consta ainda do discurso do Modelo de excelência (adotado hodiernamente por muitas escolas e instituições de 
ensino) que seu objetivo é "aceder a boas práticas e conduzir à inovação"8 . Contudo, regras como a que proíbem o uso de celulares e/ou aparelhos eletroeletrônicos durante as aulas e/ou atividades pedagógicas (a primeira do RI), se não chegam a pôr em cheque a honestidade da SME relativamente a essa meta, nos levam, no mínimo, a um exercício de elucubração na tentativa de alcançar qual seria a noção dos técnicos dessa secretaria sobre 'inovação'. Suponhamos, por exemplo, o caso de um professor de línguas que sinta a necessidade de trabalhar o vocabulário de seus alunos. Consideremos também a hipótese (não pouco provável) de a sala de leitura dessa escola não possuir dicionários suficientes para cada aluno da turma. Caso esse docente pense em inovar, estimulando os alunos que possuam smartphones a instalarem e utilizarem dicionários em seus celulares, em seu tempo de aula, precisaria transgredir a regra em questão, posto que não há nenhuma exceção quanto a essa proibição.

Outras questões que poderiam ser levantadas aqui são: (a) nesses casos, deve prevalecer o princípio da razoabilidade (ignoram-se as proibições absurdas e age-se como se não existissem) ou o zelo pelo cumprimento da lei (obedece-se a ela cegamente, como uma espécie de conteúdo atitudinal a ser passado para nossos alunos?) (b) Se é fato que os celulares e mp3 se tornaram uma realidade irreversível dentro e fora do espaço escolar, - segundo McLuhan (apud BOHN, 2013, p.92), seria "uma falácia pensar que poderíamos mergulhar no mundo tecnológico e em seguida sair dele ilesos, até o próximo mergulho" - por que insistir numa regra inócua, numa tentativa inglória de fechar a escola em si mesma, isolando-a da vida externa com muros altos, reduzindoa aos seus problemas pedagógicos, técnicos ou administrativos?

É por isso que mesmo com controvérsia, faz-se necessário considerar com gravidade as palavras de Sarlo (MOITA LOPES, 2006b, p.93) segundo quem "a escola pública é hoje o lugar da pobreza simbólica, onde professores, currículos e meios materiais concorrem em condições de muito provável derrota com os meios de comunicação de massa". Some-se a isso o fato de que a SME, como toda instituição política, incorpora e reproduz interesses ideológicos (NOVAIS, 2008) e que nem sempre o discurso reflete os reais interesses ou preocupações dos que o enunciam. No caso da SME, deve-se considerar seu empoderamento por parte daqueles que a usam no sentido de perpetuação do status quo. Assim sendo, o discurso da SME é o de "contribuir para

8 Disponível em<http://pt.wikipedia.org/wiki/Excel\%C3\%AAncia >. Acesso em: 12/12/14. 
formar indivíduos autônomos e habilitados a se desenvolver profissionalmente e como cidadãos”. Mas a prática da EM Cientista Mário Kröeff, que compõem sua rede, passou ao largo desse caminho quando da elaboração de seu RI. Percebe-se, pois, uma significativa falta de convergência de objetivos e ações quando somos informados de que o RI não resultou de um processo de discussão e decisão coletiva; antes, foi construído pela direção da escola e por alguns professores sob a orientação da SME.

Não tomamos ciência de que, em algum momento, tenha havido a participação dos demais membros da comunidade escolar: alunos, pais e funcionários, por exemplo. Portanto, por não nascer da discussão e da participação de toda a comunidade escolar, o documento sob análise carece de certo grau de legitimidade, a qual só emerge quando da participação consciente de toda a comunidade escolar (WATANABE, 1999). Onde, nesta atitude, as ações que favoreçam a formação de indivíduos autônomos? Onde o estímulo ao exercício da cidadania tanto de pais como de alunos?

\section{O DISCURSO DISCENTE}

Com base na concepção de que é preciso que aqueles que vivem as práticas sociais sejam chamados a identificar nossas questões de pesquisa como sendo válidas de seus pontos de vista (BYGATE, apud MOITA LOPES, 2006a), não poderíamos deixar de indagar aos alunos que estão submetidos a esse RI sobre o que pensavam do seu conteúdo. Estimulamos os mesmos a expressarem suas opiniões reservando para isso um tempo (45 min.) de uma das turmas, a fim de que conversássemos sobre o tema. Após os primeiros minutos - durante os quais foi preciso conversar com os alunos sobre questões como tomada de turno e momento adequado para brincadeiras, além de tentar convencer os desinteressados a participarem da pesquisa - alguns alunos emitiram suas opiniões, ora apoiando (como na proibição de captura de imagens de alunos sem a anuência do fotografado), ora opondo-se (dever levar material escolar diariamente à escola) a algumas das normas. No caso da captura de imagem (foto), a justificativa foi com base no argumento de não saberem que tipo de fim seria dado à imagem capturada indevidamente (curiosamente, uma das alunas que assim raciocinava era constantemente flagrada mexendo ao celular durante as aulas); no caso do material escolar, os alunos alegaram que por conta do peso ficava difícil cumprir essa determinação; e até 
sugeriram a colocação de armários nas dependências da escola (à maneira das escolas norte-americanas, como veem nos filmes) para que pudessem guardar neles seus materiais.

Alguns alunos, no entanto, tiveram opiniões bastante radicais em relação ao RI. Um deles, por exemplo, comentou que o RI deve ser obedecido "porque é lei; se não fosse lei ninguém ia nem te dar atenção". Essa fala foi dirigida ao professor, enquanto comentávamos sobre o primeiro item do RI, que trata da proibição do uso do celular em sala de aula; sua opinião, contudo, pode ser estendida a todos os itens: obedece-se porque é lei.

Minha jornada como professor regente, no entanto, faz-me ter uma visão diferente da expressa pelo aluno. Por limitações de tempo ${ }^{9}$, não pudemos (na medida que se fazia necessário) engajar-nos num debate de ideias como troca argumentativa e exposição de razões, para evitar a simples refutação de seu pensamento divergente (FABRÍCIO, 2006). Sua concepção sobre o fato é uma ilustração: (a) do poder disciplinador característico da modernidade, fase em que a sociedade capitalista faz aparecer todo um aparato cujo objetivo é o controle das pessoas de forma naturalizada, que se manifesta por uma aceitação implícita, não problematizada dos controles a que nos submetemos. (NOVAIS, 2008); (b) do temor da sanção que, juntamente com o olhar hierárquico e o exame, garantem o sucesso do poder disciplinar (FOCAULT, apud NOVAIS).

Tentei mostrar-lhe que nem todos os professores (ou mesmo alunos) pensam/agem com base nessa concepção. Em nossa prática docente, por exemplo, tentamos agir no sentido de que a atitude do aluno de não fazer uso do celular durante as aulas seja fruto de uma tomada de consciência (AQUINO, apud NOVAIS, 2008); ou, no caso de o usar, seja por real necessidade (pessoal ou didática), uma vez que devemos ter respeito pelo conjunto de deveres, regras e normas estabelecidas por cada sociedade em benefício da harmonia social. (NOVAIS, 2008).

\section{PARA REFLETIR}

Vemos no RI um discurso que muitas vezes atravessa aspectos da vida social de

9 Essa conversa com a turma aconteceu no último dia de aula, após a prova do $4^{\circ}$ bimestre 
um grupo de pessoas (ao proibir o uso de bonés e de minissaias, por exemplo), mas ao mesmo tempo ignora as vozes dos que a vivem (MOITA LOPES, 2006b). Em lugar de simplesmente proibir, poder-se-ia investigar, por exemplo, que significado carrega para o aluno ou aluna o uso de um boné ou de uma minissaia? O que simbolizam? Aprofundando mais a questão, não poderia a escola, ao discutir/negociar o uso desses símbolos, aproveitar a oportunidade e trabalhar tabus como reverência e sensualidade, bastante exacerbada nessa sociedade em transformação? Sobretudo, é preciso também considerar o fato de que quanto mais pessoas se envolvem na elaboração do regimento, maiores são as possibilidades de se alcançarem formas adequadas de regulação da atividade educativa (WATANABE, 1999).

Outro aspecto do RI que urge repensar é o fato de ele dialogar quase exclusivamente com o aluno, preocupando-se principalmente com seus deveres. Nesse sentido, está apenas cumprindo o papel que por séculos foi conferido à escola moderna e que até hoje muitos ainda lhe atribuem, qual seja, o de "zelar pela disciplina, pela ordem e pela obediência" (NOVAIS, 2008, p.44). E, muito embora o RI apregoe no seu preâmbulo que seu objetivo seja o de "resguardar não somente os direitos, mas também os deveres dos alunos", em nenhum momento aqueles (os direitos) são mencionados.

Assim sendo, embora possua o nome de regimento, distancia-se da sua finalidade original de ser um instrumento de organização pedagógico-administrativo, assemelhando-se mais a uma ferramenta cujo objetivo é a preservação dos princípios rígidos e centralizadores de poder (ZABOT, apud WATANABE, 1999).

Enfim, refletindo sobre a fala da diretora da escola, segundo a qual o RI está "sendo excelente para o andamento e disciplina da escola", temos a impressão de que sua maior utilidade é sua força coercitiva em situações críticas posto que, como já o dissemos, para muitas regras nele contidas (a proibição de cadarços coloridos é um exemplo emblemático) faz-se vista grossa. Chamo de situação crítica aquela em que um professor (por um motivo circunstancial) usa a lei para fazer prevalecer sua vontade por puro capricho, simplesmente porque está escrito. Exemplo disso pode ser o de proibir de fazer prova o aluno que não entrega o livro no final do ano ou barrar o aluno que chegou à sala de aula um minuto após o tempo de tolerância - ações respaldadas pelo RI sob análise.

Consideramos que já é tempo de a escola se transformar no lugar não só de 
transmissão de conteúdos teóricos, mas também de ensino de valores comportamentais (SIQUEIRA, apud NOVAIS, 2008); lugar de um ensino humanizado, que busque o bem-estar pessoal e coletivo através de uma relação de respeito entre os integrantes da comunidade escolar (NOVAIS, 2008).

\section{REFERÊNCIAS}

ALLWRIGHT, D. Six Promising Directions for Applied Linguistics. In: GIEVE, S.; MILLER, I.K. (orgs.). Understanding the Language Classroom. Hampshire: Palgrave Macmillan, p.11-17. 2006.

ANTÚNEZ, S. ¿ Que proyecto hacemos ? Cuadernos de Pedagogia, nr. 158 (abril), p.10-2. 1988.

AQUINO, J.R.G. Confrontos na Sala de Aula: Uma leitura Institucional da relação professor-aluno. São Paulo: Summus Editorial, 1996.

BOHN, H.I. Ensino e aprendizagem de línguas: os atores da sala de aula e a necessidade de rupturas. In: MOITA LOPES, L.P. (Org.). Por uma Linguística Aplicada Indisciplinar. São Paulo: Parábola Editorial. 2013.

BYGATE, M. Some Current Trends in Applied Linguistics. Towards a Generic View, AILA Review, vol. 17: 6-22. 2004.

DAVIES, A. An introduction to applied linguistics. From practice to theory. Edinburgh: Edinburgh University Press. 1999.

DUARTE, N. Vigotski e o "aprender a aprender": crítica às apropriações neoliberais e pós-modernas da teoria vigotskiana. Campinas: Aurores Associados. 2006.

FABRÍCIO, B.F. Linguística Aplicada como espaço de "desaprendizagem": redescrições em curso. In: MOITA LOPES, L.P. (Org.). Por uma Linguística Aplicada Indisciplinar. São Paulo: Parábola Editorial. 2006.

FOUCAULT, M. [1975]. Vigiar e punir. 22a. ed. Petrópolis:Vozes, 2000.

FREIRA, M.M; LEFFA, V.J. A auto-heteroconformação tecnológica. In: MOITA LOPES L.P. (Org.). Linguística Aplicada na Modernidade Recente: festschrift para Antonieta Celani. São Paulo: Parábola Editorial. 2013.

INSTITUTO LATINO-AMERICANO DAS NAÇÕES UNIDAS PARA PREVENÇÃO DO DELITO E TRATAMENTO DO DELINQÜENTE (ILANUD) - com colaboração da Justiça Global (?). Violência Institucional - Quando o Estado agride a criança. [S.L.] 
McLUHAN M. Os meios de comunicação como extensões do homem. Trad.: D. Pignatari. São Paulo: Cultrix. 2007.

MOITA LOPES, L.P. Fotografias da Linguística Aplicada brasileira na modernidade recente: contextos escolares. In: MOITA LOPES L.P. (Org.). Linguística Aplicada na Modernidade Recente: festschrift para Antonieta Celani. São Paulo: Parábola Editorial. 2013.

MOITA LOPES, L.P. Linguística Aplicada e vida contemporânea - problematização dos construtos que têm orientado a pesquisa. In: MOITA LOPES L.P. (Org.). Linguística Aplicada na Modernidade Recente: festschrift para Antonieta Celani. São Paulo: Parábola Editorial. 2013. (2006b.)

MOITA LOPES, L.P. Uma Linguística Aplicada mestiça e ideológica - interrogando o campo como linguista aplicado. In: MOITA LOPES, L.P. (Org.). Por uma Linguística Aplicada Indisciplinar. São Paulo: Parábola Editorial. 2006 a.

NOVAIS, E.L. A construção discursiva da (in)disciplina na perspectiva bakhtiniana: vozes, discursos e alteridade no contexto escolar. Tese (Doutorado em Letras) - Pontifícia Universidade Católica do Rio de Janeiro, Rio de Janeiro. 2008.

REBELO, R. A. A. Indisciplina escolar: causas e sujeitos. Petrópolis: Vozes. 2002. SARLO, B. Cenas da vida pós-moderna. Intelectuais, arte e videocultura na Argentina. Rio de Janeiro. Editora UFRJ. 2000.

SIQUEIRA, D. C. T. Relação professor-aluno: uma revisão crítica. Disponível em $<$ www.educacional.com.br.> Acessado em 20/05/06.

SOUZA, M.T.B.T.G. A função social da escola no contexto atual: a experiência de duas escolas públicas paulistanas. Gestão-Ação, Salvador, v. 7, no. 3, p 279-289, set/dez, 2004.

VIDAL, J.E., CÁRAVE, G. FLORENCIO, M.A. El proyecto educativo de centro: una perspectiva curricular. Madrid: Editorial EOS. 1992.

WATANABE, T. Papel do Regimento Escolar na organização e funcionamento da escola pública. Tese (doutorado). Universidade Estadual de Campinas. Faculdade de Educação. 1999.

ZABOT, N. O Regimento Escolar como instrumento de organização administrativa e pedagógica da comunidade escolar. Revista brasileira de administração da educação. v.4, n.2, p.63-6, jul-dez. 1986.

\section{O AUTOR}

Alexandre Florencio dos Santos é professor nas redes públicas municipais de Duque de Caxias e do Rio de Janeiro; mestrando em Estudos da Linguagem (PUC-Rio) e pós- 
graduado em História e Cultura afrodescendente (PUC-Rio). Possui graduação e licenciatura em Letras pela Universidade do Estado do Rio de Janeiro. Atualmente é bolsista do CNPq - Conselho Nacional de Desenvolvimento Científico e Tecnológico Brasil.

E-mail: aflorencio_br@msn.com 


\title{
ANEXO 1
}

\section{REGIMENTOO INTERNO}

\author{
Srs. Responsáveis e alunos,
}

$\dot{E}$ um prazer recebê-los em nossa Escola. Desejamos que vocês sejam muito felizes aqui e que nossa convivência seja pautada no respeito, na confiança e na troca. Um diálogo franco é sempre o melhor caminho $€$ é essa a forma com a qual nos relacionamos com a Comunidade.

A fim de que nosso ano letivo transcorra da melhor maneira, gostariamos de sinalizar algumas regras adotadas 15 de abril de 2010 do não somente os direitos, mas também os deveres 04 de janeiro de 2009. Essas regras têm por objetivo resguardar somente os direitos, mas também os deveres dos alunos. Vejamos quais são:

É proibido o uso de celulares e lou aparelhos eletroeletrônicos durante as aulas elou atividades pedagógicas conforme a Lei 4734, assim como o Regimento Interno, ambos citados acima;

peolagógicos, culminâncias de projotos) de alunos(as) nas dependências da U.E., salvo em eventos É proíbido o uso de bonés, roupas cotos e registro de aulas com utilização de mídias;

- $\quad$ - proíbido o uso de bonés, roupas coloridas, shorts e minissaias, vetados pelo Regimento Interno;

de Janeiro, calca ou bermuda jeans Regimento interno é camisa com o logotipo da Prefeitura do Rio azul marinho; tênis (preferêncians na altura do joelho (sem strass, bordados e pinturas), preta elou Prefeitura;

(quebra de objetos elou sanitários Interno Escolar, todo dano elou prejuizo ao patrimônio público (quebra de objetos e/ou sanitários e vidros, pichação ou rabisco em paredes, portas, materiais, ser ressarcido pelo responsável do aluno;

Para as aulas de Educacão Fisica, camis

heianca ou com logotipo da Prefeituramisa de malha branca (com ou sem manga) e bermuda cie para as atividades físicas escolares; para as atividades físicas escolares;

caso de nossa escola. Lembremo-nos que nosso tados inadequados ao espaço escolar, sobretudo no Não será permitido o uso de cadarcos que nosso espaço físico tem escadas:

Os materiais escolares de cadarços coloridos;

com o aluno, a fim de que haja participacão deveräo ser trazidos diariamente para a Escola, junto fazem parte deste material, assim como o kit escoliva dos mesmos nas aulas. Os cadernos pedagógicos Os alunos estão recebendo livros como o kit escolar e os livros didáticos;

en excelentes condiçōes de uso. Desta form. O livro didático deverá ser devolvido ao fiñal do ano encapem e coloquem nome e turma: Horário dos alumos da Horário dos alunos da Educação Especial: das 7:30 às 11:30, no $1^{\circ}$ turno e das $13 \mathrm{~h}$ às $17 \mathrm{~h}$ no $2^{\circ}$
turno. Tolerância máxima de 20 minutos.

no $2^{\circ}$ turno. Tolerância máxima de 20 minutos;

- Lembramos que tanto o Conselho Tutelar quanto

pais e responsáveis devem ter pais e responsáveis devem ter, no que se refere ao horário de entrada e de saída do(a) aluno(a),

evitando, assim, atrasos e faltas que ocasionem prejuizo à aprendizagem do(a) mesmo(a);
Nenhum(a) aluno(a) sairá da Unidade Escolar antes do horário de saída. Se for necessário, o responsável deverá vir buscar e/ou enviar um bilhete, devidamente assinado e com telefone para contato;

- Não será tolerada nenhuma forma de bullying, discriminação de qualquer forma e agressão verba é fundamental para qualquer bom relacionamento;

- Todo e qualquer problema ocorrido nas dependências da Escola deverá ser encaminhado diretamente à Direçăo, para que esta possa solucioná-lo;

- Sempre que houver mudança de endereço elou de número telefônico, a Escola deverá ser avisada, pois, em casos de emergências, é importante estabelecermos um contato rápido com as famílias:

Se houver necessidade de faltar, o(a) responsável do(a) aluno(a) deverá justificar a falta. Só são abonadas as faltas médicas, comprovadas com atestado ou receita médica. Se houver um problema com o(a)

Ero

sem estar acompanhado de um funcionár documento que apresente foto.

\section{Contamos com sua colaboração.}

Atenciosamente,

A Direção. 